\title{
Recovery from postpartum psychosis: a systematic review and metasynthesis of women's and families' experiences
}

\author{
R. Forde ${ }^{1,2} \cdot$ S. Peters ${ }^{1} \cdot$ A. Wittkowski ${ }^{1,2}$
}

Received: 30 October 2019 / Accepted: 26 January 2020 / Published online: 4 February 2020

(C) The Author(s) 2020

\begin{abstract}
Postpartum psychosis is a serious disorder that can result in adverse consequences for the mother and baby. It is important that we understand the experiences of women, to develop effective interventions during this critical period. The aim of this systematic review was to conduct a metasynthesis of qualitative research exploring women's experiences of postpartum psychosis and factors involved in recovery from the perspective of women and family members. A comprehensive literature search of five databases was conducted and the findings were appraised and synthesised, following a thematic synthesis approach. Fifteen studies, capturing the views of 103 women and 42 family members, met the inclusion criteria. Four main themes incorporating 13 subthemes were identified following synthesis: (1) Experiencing the unspeakable, (2) Loss and disruption, (3) Realigning old self and new self and the integrative theme of (4) Social context. The findings offer new insight into the unique experience of postpartum psychosis and demonstrate that recovery does not follow a linear path. To improve clinical outcomes, a more integrative and individualised approach is needed which incorporates long-term psychological and psychosocial support, and considers the needs of the family. Further areas for staff training, service development and future research are highlighted.
\end{abstract}

Keywords Literature review $\cdot$ Qualitative research $\cdot$ Perinatal mental health $\cdot$ Psychotic disorder $\cdot$ Childbirth

\section{Introduction}

Postpartum psychosis (PP) is one of the most severe mental health problems following childbirth, affecting 0.89 to 2.6 per 1000 women (Vanderkruik et al. 2017). It is characterised by a dramatic onset, and rapid deterioration, with symptoms including hallucinations, delusions, disorganised behaviour and depression (Di Florio et al. 2013; Heron et al. 2008; Sit et al. 2006). Continued poor maternal mental health is associated with increased risk of adverse outcomes including suicide and decreased mother-infant bonding (Wilkinson et al. 2017). Immediate referral to a secondary mental health service for

A. Wittkowski

anja.wittkowski@manchester.ac.uk

1 Divison of Psychology and Mental Health, School of Health Sciences, Faculty of Biology, Medicine and Health, Manchester Academic Health Science Centre, The University of Manchester, 2nd Floor Zochonis Building, Brunswick Street, Manchester M13 9PL, UK

2 Greater Manchester Mental Health NHS Foundation Trust, Manchester, UK assessment is therefore recommended (NICE 2018). Inpatient care, ideally within a Mother and Baby Unit (MBU; Gillham and Wittkowski 2015) and pharmacological intervention, is almost always required (NICE 2018; Jones and Smith 2009). Family members are reported to be integral during this process and should be involved in care and treatment planning (Engqvist and Nilsson 2014; Mohamied 2019).

With appropriate treatment, the most severe symptoms usually resolve within 2 to 12 weeks (Bergink et al. 2015). However, women remain at increased risk of subsequent postpartum and non-postpartum episodes, including depression and anxiety (Robertson et al. 2005; Nager et al. 2013). PP is a highly stressful life event which can have a detrimental impact on well-being and long-term functioning and result in feelings of guilt, loss, fear and shame (Burgerhout et al. 2017; Plunkett et al. 2016; Wittkowski et al. 2014). Psychological intervention and psychosocial support has been recommended (Doucet et al. 2011), yet very little is known about the psychological factors underpinning recovery or the types of intervention found to be effective.

Previous metasyntheses have explored individuals' experiences of serious mental health problems and mental health 
services in the postnatal period (Ruffell et al. 2019; Smith et al. 2018; Plunkett et al. 2016; Megnin-Viggars et al. 2015; Wittkowski et al. 2014; Dolman et al. 2013). However, given the range of maternal mental health disorders included in those reviews, the applicability of these findings to women's experiences of PP remains unknown. Thus, this systematic review and metasynthesis of published qualitative studies was conducted with the aims of (a) synthesizing the reported experiences of PP from the perspectives of women and family members and (b) identifying factors involved in recovery. The outcomes of which should be used to inform policy, practice and intervention development (Moore et al. 2015; Tong et al. 2012).

\section{Method}

A metasynthesis was deemed most appropriate to systematically analyse and interpret multiple qualitative studies with the aim to develop new insight (Lachal et al. 2017). The review protocol was registered with PROSPERO on 19 December 2018 (Ref: CRD42018119145).

\section{Inclusion and exclusion criteria}

All published empirical studies exploring women's or family members' experiences of PP and/or recovery using a qualitative methodology were included. Studies published in any language were eligible for inclusion, as were studies using mixed methods, provided qualitative data could be extracted.

Studies were excluded when they (1) explored 'schizophrenia' and other perinatal disorders, such as postnatal depression; (2) did not stipulate the diagnosis; (3) used a mixed sample in which it was not possible to differentiate the findings based on diagnosis; (4) explored only health professionals' views; or (5) were unpublished research or grey literature.

\section{Search strategy}

Five databases CINAHL, MEDLINE, EMBASE, PsychINFO and Web of Science were searched from inception to 3 April 2019. An updated search was completed on 20 August 2019 which revealed no additional eligible studies. Only keywords relating to the 'phenomenon of interest' (Cooke et al. 2012) were applied to ensure all relevant studies were captured ('postpartum psychosis' OR 'puerperal psychosis' OR 'postnatal psychosis' OR 'psychosis after childbirth') and no limits were applied. Additional studies were sought from the reference lists of included studies using forward and backward searching (Horsley et al. 2011).

\section{Study selection}

The search process, following PRISMA guidelines (Moher et al. 2009) yielded 1782 unique studies (see Fig. 1). The title, keywords and abstracts of all studies were assessed for eligibility against the inclusion/exclusion criteria; 1728 studies were subsequently excluded. A random $20 \%$ of studies $(n=$ 353) were checked by an independent rater and a strong level of inter-rater reliability was obtained $(96 \%, \mathrm{k} 0.88$ (95\% CI, 0.82-0.95) McHugh 2012). Of the remaining 54 studies, 39 were excluded when reviewed in full, yielding a final sample of 15 .

\section{Critical appraisal}

The methodological quality of the included studies was evaluated using the Critical Appraisal Skills Programme (CASP 2018) checklist. The CASP comprises ten questions across three broad domains, relating to the validity, design and utility of the results. The CASP was used to determine rigour and trustworthiness in the outcomes (Hannes 2011).

\section{Data analysis}

All included studies were extracted electronically onto NVIVO 12 (2018) data management software and analysed using Thomas and Harden's (2008) thematic synthesis (see Table 1). This approach enabled the researchers to integrate multiple qualitative findings and identify recurring themes, following three key overlapping stages (Noyes et al. 2018; Ring et al. 2011). Distinctions were made across the different samples when analysing the data and constant comparisons were made across and within the women's and family members' accounts to ensure similarities and differences were captured. To test the credibility and applicability of the findings, a peer and member-checking exercise was completed during theme development stage (Lincoln and Guba 1985; Creswell and Miller 2000).

\section{Results}

\section{Study characteristics}

The qualitative synthesis comprised 15 studies reporting the experiences of 103 women and 42 family members, of which 32 were partners (see Table 2). All studies were published between 2003 and 2018. Ten studies were conducted in the UK, two in Sweden, two in the USA and Canada and one used online data (location unknown). A diverse sample was obtained, in which women who participated in the studies were reported to be at different stages of their recovery, ranging from 2 months postpartum to 32 years. No women were 
Fig. 1 Summary flowchart of study selection and search outcomes
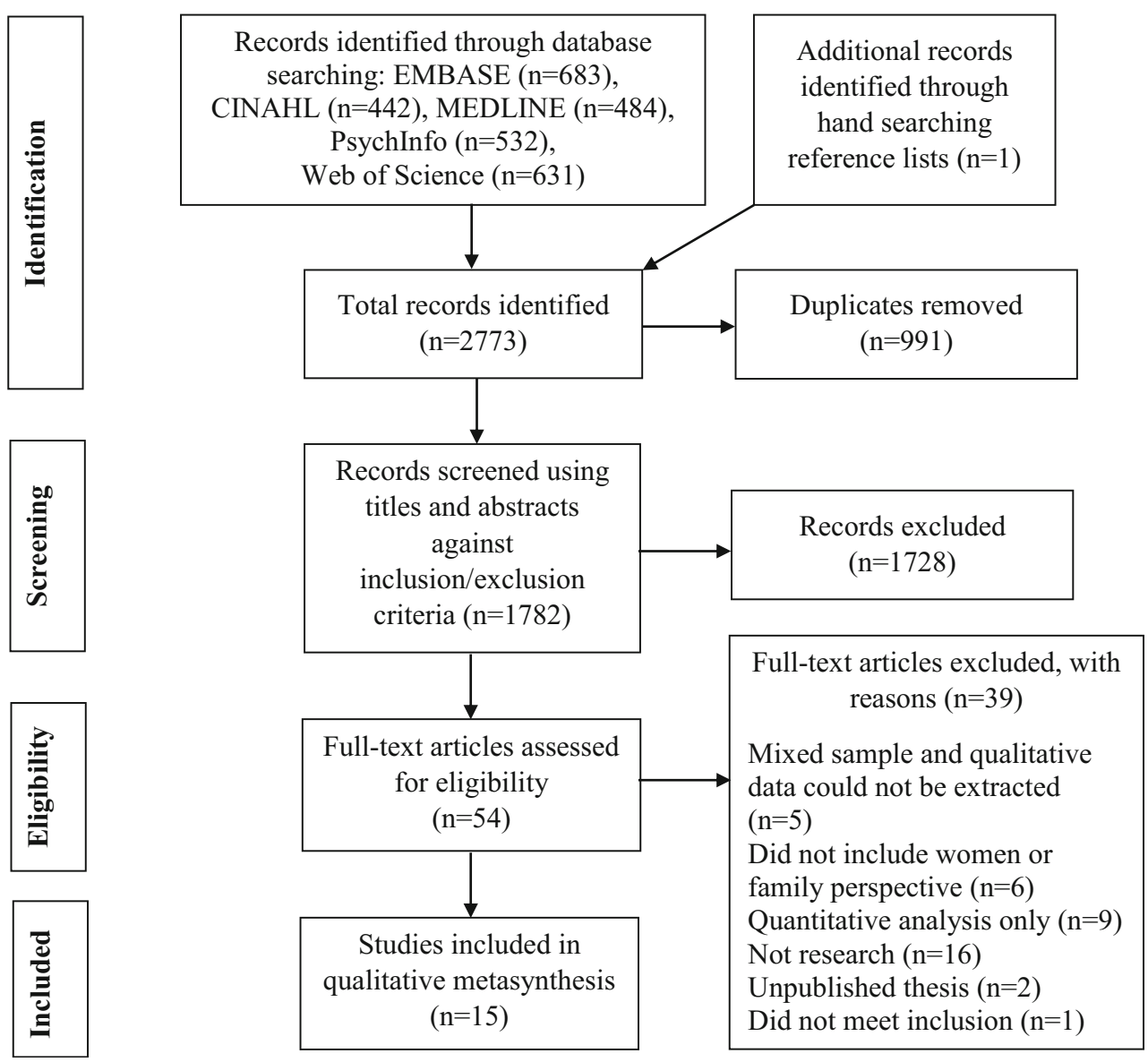

reported to be actively psychotic during the interview and this was frequently cited as an exclusion criteria to ensure informed consent could be obtained. Engqvist et al. (2011) used online narratives as a data source and therefore the duration since onset could not be determined. The duration since onset reported by family members was also broad, capturing experiences up to 19 years postpartum. One study (Boddy et al. 2016) specifically sought individuals' experiences during the acute phase of psychosis and this was obtained from the perspective of fathers only.

Using the CASP checklist, no major methodological issues were identified and all 15 studies were rated to have high methodological quality and low methodological bias (see Table 3).

\section{Synthesis}

Four main themes and 13 subthemes were conceptualised in the metasynthesis, representing the reported experience of PP and factors involved in recovery from the perspective of women and family. A conceptual model was developed (see Fig. 2) to provide a visual representation and to illustrate the relationships between themes. This captured themes from both women and family members, due to the similarities found in some
Table 1 Thematic synthesis process
Stages of thematic synthesis

1 Free line-by-line coding completed inductively across all data contained within the 'findings/results' sections of each study, including participant quotes, author narrative and interpretation. The women's accounts were coded first, followed by those of family members. New concepts were created according to the meaning and content of each sentence.

2 These codes were then organized into related areas and descriptive themes were developed, using an iterative process which involved the refinement of codes, checking for consistency of interpretation.

3 Higher level analytical themes were generated with the aim of producing new interpretations and key messages as guided by the research aims. This was continuously reviewed until a final set of analytical themes that captured the key meanings across the women's and family members' accounts were agreed upon. 


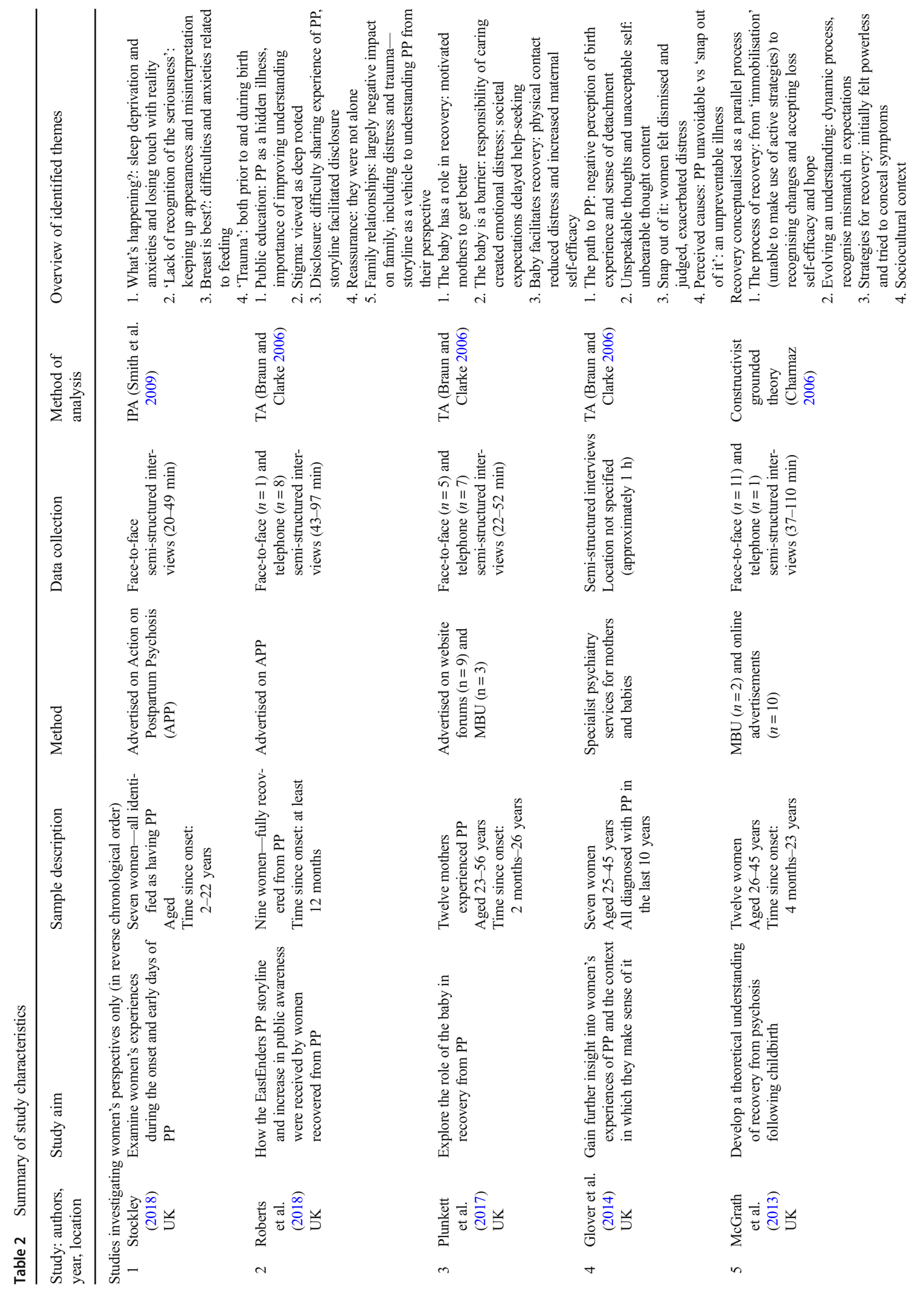




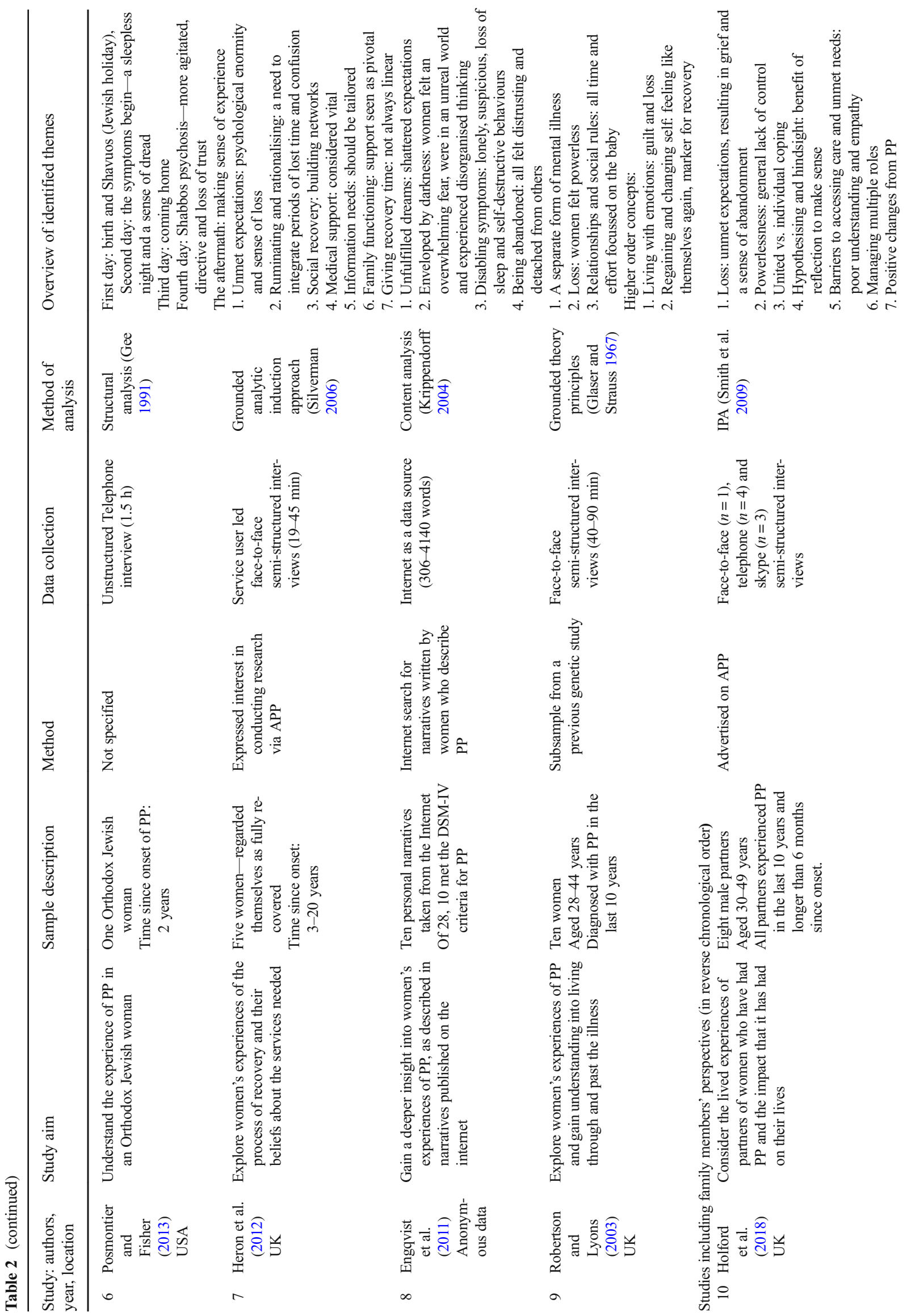




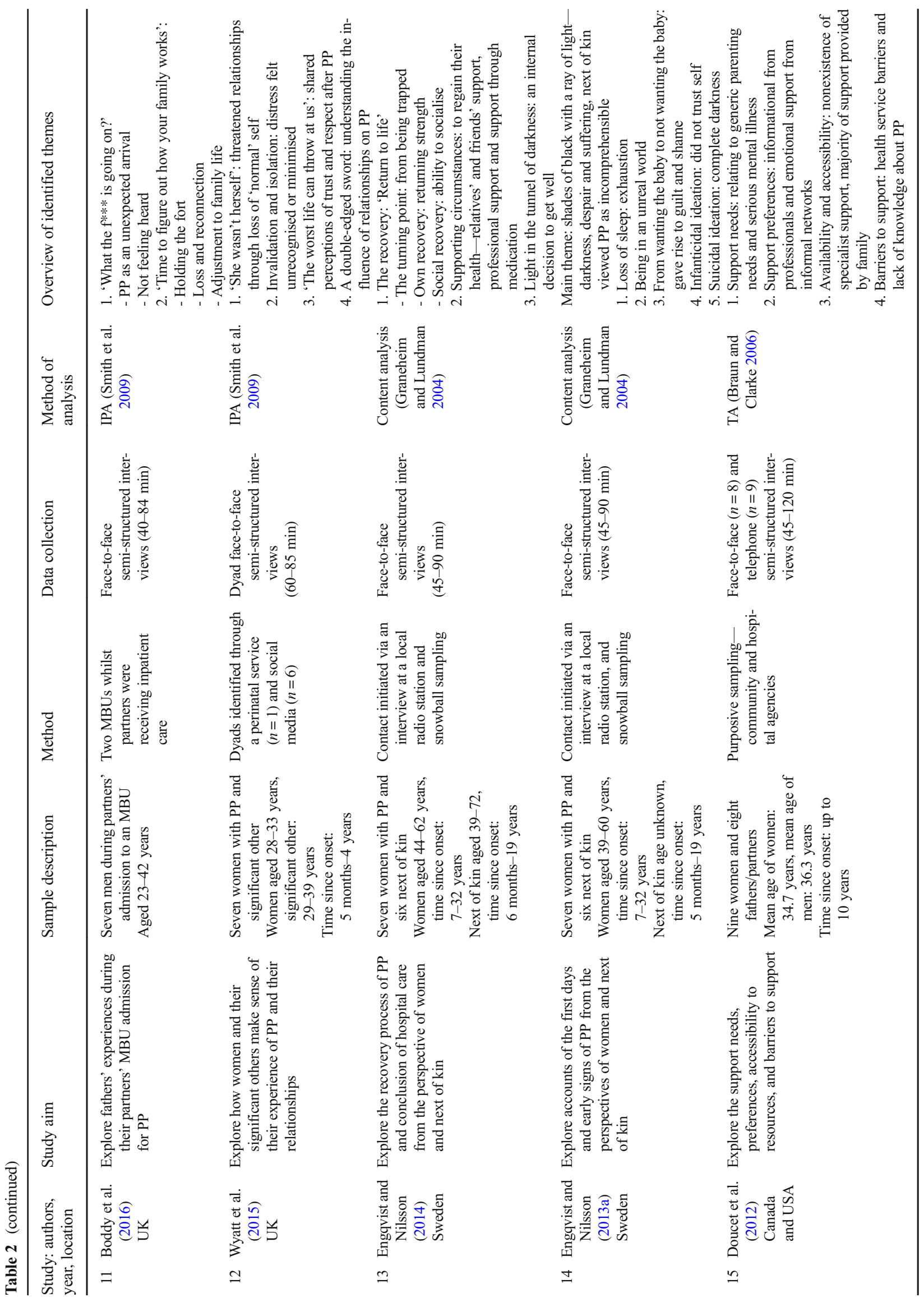


Table 3 Outcomes of the CASP checklist for the 15 qualitative studies included in the metasynthesis

$\begin{array}{lllllllllllllll}1 & 2 & 3 & 4 & 5 & 6 & 7 & 8 & 9 & 10 & 11 & 12 & 13 & 14 & 15\end{array}$

1. Was there a clear statement of the aims of the research?

Yes Yes Yes Yes Yes Yes Yes Yes Yes Yes Yes Yes Yes Yes Yes

2. Is a qualitative methodology appropriate?

Yes Yes Yes Yes Yes Yes Yes Yes Yes Yes Yes Yes Yes Yes Yes

3. Was the research design appropriate to address the aims of Yes Yes Yes Yes Yes Yes Yes Yes Yes Yes Yes Yes Yes Yes Yes the research?

4. Was the recruitment strategy appropriate to the aims of the Yes Yes Yes Yes Yes PA* Yes Yes Yes Yes Yes Yes Yes Yes PA* research?

5. Was the data collected in a way that addressed the research Yes Yes Yes PA* Yes Yes Yes Yes Yes Yes Yes Yes Yes Yes PA* issue?

6. Has the relationship between researcher and participants Yes Yes PA* No Yes Yes PA* Yes Yes Yes Yes Yes Yes No No been adequately considered?

7. Have ethical issues been taken into consideration?

8. Was the data analysis sufficiently rigorous?

9. Is there a clear statement of findings?

10. How valuable is the research?

Yes Yes Yes Yes Yes PA* Yes Yes PA* Yes Yes Yes Yes Yes Yes

Yes Yes Yes Yes Yes Yes Yes Yes Yes Yes Yes Yes Yes Yes Yes

Yes Yes Yes Yes Yes Yes PA* Yes Yes Yes Yes Yes Yes Yes Yes

Yes Yes Yes Yes Yes Yes Yes Yes Yes Yes Yes Yes Yes Yes Yes

$* P A=$ partially agree

of their experiences. The model demonstrates women's nonlinear progression towards recovery, in which they often moved back and forth between phases and this process was integrated within the wider social context. Illustrative quotes are provided below each theme with additional data presented in Table 4.

\section{Theme 1: experiencing the 'unspeakable'}

During the initial stages of PP, women reported 'shock' (Women p.157; Heron et al. 2012) and their experiences were conceptualised as 'unspeakable' (Author p.260; Glover et al. 2014).

Fig. 2 A conceptual model of women's and family members' experiences of postpartum psychosis and the factors involved in recovery

\section{'Trapped in an insane mind'}

Women reported a range of distressing thoughts, which often related to their newborn baby 'Did I kill my baby?' (Woman p.240; Doucet et al. 2012). Women reported experiencing racing thoughts and unusual perceptions; they worried that their baby would be taken away from them and felt 'trapped in an insane mind' (Woman p.380; Engqvist et al. 2011). These fears led women to mistrust people close to them and attempts to conceal their symptoms contributed to delays in families seeking help. Partners reflected that they missed earlier sign and referred to a key, sometimes 'traumatic' moment (Partner p.402; Boddy et al. 2016), where it became clear they needed help.

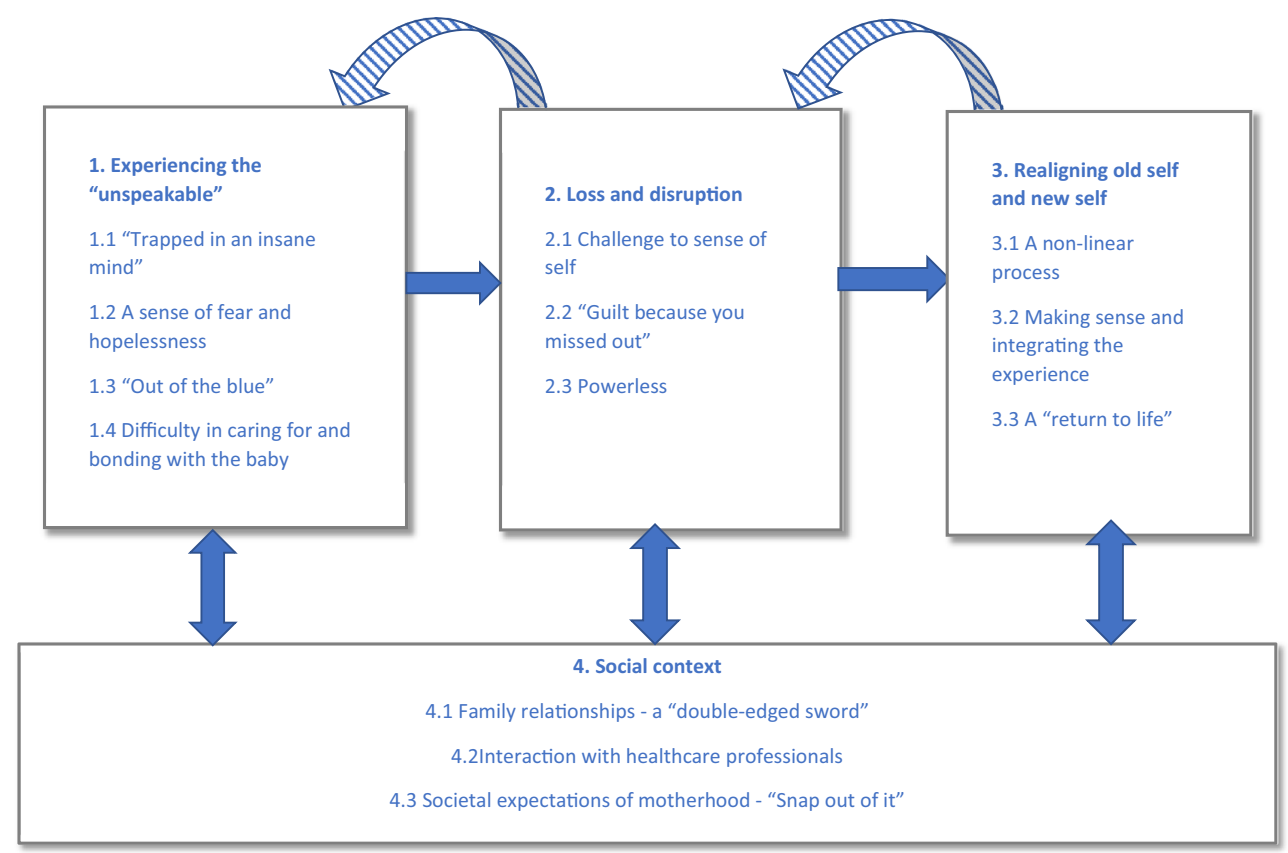


Table 4 Thematic structure with Illustrative quotes

Theme $\quad$ Illustrative quotes

Theme 1: experiencing the 'unspeakable'

1.1: 'Trapped in an insane mind'

'For in my paranoia I was certain that my husband (who really is one of the world's greatest men and husbands) was out to get me. I thought he wanted to divorce me and take our child. I thought he was probably sabotaging our efforts to get help. This man, who I trust more than anyone in the world, I felt I could not trust' (Woman p.383; Engqvist et al. 2011).

'It feels like it happened to another person, it's hard for me to say how I felt. I felt like, throughout most of it... like I was watching someone else do it' (Woman p.155; Stockley 2018).

'She was ranting and raving and my friends.. .. both looked at me and I was like, what the fuck is going on' (Partner p.402; Boddy et al. 2016).

1.2: A sense of fear and hopelessness

'I just felt very lonely, very homesick. I felt like no one was really paying attention to me. I was just thrown into this place... left all alone not knowing how to cope or what to do or anything' (Woman p.171; Posmontier and Fisher 2013).

1.3: 'Out of the blue'

'If I'd known about it [postpartum psychosis] I'd probably have, I'm not saying it would have stopped it, but it probably would have helped to understand a little thinking 'this is what I'm having', because obviously if you have never heard of anything and you go off your rocker, you think my God, what is wrong?' (Woman p.80; Roberts et al. 2018).

1.4: Difficulty in caring for and bonding with the baby

'I wanted to go to sleep so I would turn over, and I'd be like, I do not want to be with him [baby] now' (Woman p.1103; Plunkett et al. 2017).

'It was a horrible feeling. I felt like her milk was dirty and I used to forget. My memory went, I would forget everything... I do not know how many bottles I threw away 'cause I was so paranoid of making the baby sick. I was paranoid about everything'. (Woman p.156; Stockley 2018)

'I found for a long time it was at least a two-person job to manage things. Because one person had to take care of the baby, and usually I had to take care of my wife' (Partner p.241; Doucet et al. 2012).

'This was something completely different. I thought she handled our son recklessly. She held him almost as if he were a doll' (Partner p.85; Engqvist and Nilsson 2013a).

Theme 2: loss and disruption

2.1: Challenge to sense of self

'Your whole being, how you see yourself, the kind of person you are, and your whole sense of identity is completely devastated really, because you will have behaved in ways that shock you completely. I'm not a, you know, successful person anymore that I thought I was, I'm now a mental health patient' (Woman p.158; Heron et al. 2012).

'My daughter became a complete stranger. She was totally deflated... It seemed as if she was totally lost in the world. You just do not know what to do. It was difficult to get through to her and in [a] way she was inside a fog all by herself' (Parent p.85; Engqvist and Nilsson 2013a).

'I worried about interaction. I worried that I'd never get better from the depression because it was very cyclical. I really, really worried about the impact on [my baby] because I'd read about mums who have mental health problems affecting their kids, I worried about the genetic side of it. What did not I worry about? I worried for my marriage, all sorts of stuff like that really. I worried for the future really - being ill, thinking am I always, at that point because, I did think that I was never going to get better, so that was my main sort of fear' (Woman p.158; Heron et al. 2012).

2.2: 'Guilt because you missed out'

'All these feelings of guilt because you missed out, or not being there, for your new born baby, and guilty, because you left your husband to deal with it all when it's the first time for him as well' (Woman p.157; Heron et al. 2012).

'You would think that the first time after having a baby you go round obviously showing her off to everybody, and we could not do that purely because [the mother] wasn't there' (Partner p.3; Holford et al. 2018).

2.3: Powerless

'My family said I wasn't well and that I needed to take tablets but they never explained to me why or what that illness was... No leaflets, no information, and well the attitude was quite, you know, take the tablets and do not say nothing' (Woman p.160; Heron et al. 2012).

'For the first five days, all I got was, 'you are not married, your son's not registered, you have got no right to know where they are or what's going on' (Partner p.403; Boddy et al. 2016).

Theme 3: realigning old self and new self 3.1: A non-linear process

'I thought 'I'm out of the woods' you know... 'yeah it's all going to be fine', and then actually the depression afterwards, the deep, deep depression afterwards, was just such a blow, such a double whammy' (Woman p.162; Heron et al. 2012).

3.2: Making sense and integrating the experience

'At least I wanted someone to talk to, which I got when my son was about one year old. And I concluded this contact now, barely three weeks ago. So, it has taken 18 years to deal with this backpack of mine...!' (Woman p.12; Engqvist and Nilsson 2014). 
Table 4 (continued)

\begin{tabular}{|c|c|}
\hline Theme & Illustrative quotes \\
\hline & $\begin{array}{l}\text { 'I'm now a specialist in postpartum psychosis medication involved, because I am one of those people who } \\
\text { will research in terms of Google and APP networks and whatnot. I guess that had been my idea of finding } \\
\text { out what is actually going on' (Partner p.5; Holford et al. 2018). } \\
\text { 'I actually saw a bloke who was a trainee clinical psychologist, but he was brilliant. He just gave me time to } \\
\text { cry and be upset and talk about all these worries. And with CBT, which is a sort of talking treatment, he } \\
\text { helped me to find different ways into that negative cycle of worries' (Woman p.159; Heron et al. 2012). }\end{array}$ \\
\hline 3.3: A 'return to life' & $\begin{array}{l}\text { 'I just feel very proud of myself' (Woman p.174; Posmontier and Fisher 2013). } \\
\text { 'Slowly, my wife was becoming her old self once again' (Partner p.12; Engqvist and Nilsson 2014). } \\
\text { 'I can stand back and look at myself in the past when I was ill and that is not me. I went from being a } \\
\text { confident woman to, I cannot think of a word, well erm pathetic that's what I was, now I've regained my } \\
\text { confidence and I feel better than I did before because I've been through this and come out stronger. } \\
\text { Nothing as bad can ever happen to me again' (Woman p.424, Robertson and Lyons 2003). }\end{array}$ \\
\hline \multicolumn{2}{|l|}{ Theme 4: social context } \\
\hline $\begin{array}{l}\text { 4.1: Family relationships - a 'double-- } \\
\text { edged sword' }\end{array}$ & $\begin{array}{l}\text { 'If they [family] understand then they will just step up more' (Woman p.239; Doucet et al. 2012). } \\
\text { 'I needed advice on how to handle the illness and what to say. Also, information on the early signs of relapse } \\
\text { to watch for and if it was to the point that I needed to get help' (Partner p.241; Doucet et al. 2012). } \\
\text { 'It's as if I did not have enough love to go round and so I gave it all to my son' (Woman p.421; Robertson } \\
\text { and Lyons 2003). }\end{array}$ \\
\hline $\begin{array}{l}\text { 4.2: Interaction with healthcare } \\
\text { professionals }\end{array}$ & $\begin{array}{l}\text { 'I was on a very high dose of Olanzapine and it just knocks you out and makes you into a complete zombie. } \\
\text { The psychiatrist was a young guy not understanding that we had needs as a family. My husband really } \\
\text { needed me to be awake enough to get my baby dressed and you know, do that kind of stuff' (Woman } \\
\text { p.159; Heron et al. 2012). } \\
\text { 'Those places [MBU] are a lifesaver, because if you are not in that specialism no one else can really } \\
\text { understand' (Partner p.7; Holford et al. 2018). } \\
\text { 'That would be the number one reason for me not telling anyone. Cos I was utterly convinced if I told the } \\
\text { doctor I am thinking of throwing my baby out of the window ... they are going to think 'Oh my god that } \\
\text { poor baby.' And you know you hear that from the paper that they were taken away and that's it. I did not } \\
\text { tell a soul' (Woman p.1103; Plunkett et al. 2016) }\end{array}$ \\
\hline $\begin{array}{l}\text { 4.3: Societal expectations of } \\
\text { motherhood-'Snap out of it' }\end{array}$ & $\begin{array}{l}\text { 'I feel that people often think it's postnatal depression, and they do not understand it at all. It's taken me } \\
20 \text { years of really banging my head against the wall trying to make people aware of it' (Woman p.77; } \\
\text { Roberts et al. 2018). } \\
\text { 'There was never much discussion, even from family, but certainly not from any of the medical services, as } \\
\text { to how I was, what concerns did I have. I was very much left to feel that you have got to cope' (Partner } \\
\text { p.6; Holford et al. 2018). }\end{array}$ \\
\hline
\end{tabular}

\section{A sense of fear and hopelessness}

Many women described their experience as traumatic, frightening and overwhelming 'I never knew this kind of fear or darkness existed' (Woman p.381; Engqvist et al. 2011). This sense of fear was often exacerbated by women's hospital admission and associated separation and isolation from their family 'I thought I was on my way to hell on earth' (Woman p.381; Engqvist et al. 2011). Women described feeling out of control and worried they were 'never going to get better' (Woman p.158; Heron et al. 2012). A similar sense of hopelessness was reported by the family:

When everything is just dark, and every day is a hell to get through, then it's tough. It's terrible. The days are hopeless (Father p.87; Engqvist and Nilsson 2013a).

\section{'Out of the blue'}

Women and family members consistently reflected on the sudden and severe escalation of PP. They reported having minimal to no information prenatally, which added to their sense of being unprepared. As women and family members tried to make sense of why the woman had developed PP, many attributed the diagnosis to a biological cause involving a hormonal imbalance and factors related to pregnancy, such as sleep disturbance or a traumatic birth experience. These birthspecific attributions helped women and families to view $\mathrm{PP}$ as a disorder specific to childbirth that can happen 'out of the blue' to anyone (Woman p.78; Roberts et al. 2018), thereby externalising the cause and reducing selfblame. 


\section{Difficulty in caring for and bonding with the baby}

During the early phase of PP, many women experienced increased anxiety, reduced confidence and reported delays bonding with their babies. Women described meeting their babies' physical needs, but with a sense of detachment:

I fed him, bathed him, changed him and was able to make up his feeds, but I had no real affection for him (Woman p.383; Engqvist et al. 2011).

Women reflected on how difficult they found caring for their baby, when they were extremely exhausted themselves and sedated from medication or fearful of accidentally causing harm. As a result, women often relied on family members and nursing staff to provide practical care for their baby. For some partners, providing the level of support needed for both their baby and partner became extremely challenging:

I honestly don't think I could have survived much longer (Partner p.4; Holford et al. 2018).

MBU admission was often described as a relief for family members because they believed both the woman and baby were safe and being cared for.

\section{Theme 2: loss and disruption}

Women and family reported a sense of loss and disruption that permeated across multiple areas of their lives and remained with women beyond the remission of their acute psychotic symptoms.

\section{Challenge to sense of self}

The experiences associated with the acute stage of PP challenged women's sense of self and personal identity. Women and family members described the woman's presentation as being significantly out of character and resulting in feelings of loss, abandonment and fear for the future:

I did not recognise her at all... it just wasn't her... I was just terrified....that I had lost her (Partner p.4; Holford et al. 2018).

Women's experiences of loss remained with them beyond recovery and women believed they had 'undergone a change that was likely permanent' and this change required acceptance (Woman p.340; McGrath et al. 2013).

\section{'Guilt because you missed out'}

As time progressed, women reflected on multiple losses. In particular, they believed they had missed out on the first few months of their child's life and worried about the impact of this on their child's development. Many women and partners described guilt and disappointment resulting from unfulfilled expectations of parenthood. Some reported a sense of shame for the initial thoughts they had about their baby: 'I was appalled that I could have such an awful thought' (Woman p.382; Engqvist et al. 2011). Some parents decided against having further children due to the increased risk of a subsequent episode of PP. A decision that was often associated with additional feelings of sadness and loss:

I loved being pregnant and I loved carrying a child... not to do that is heartbreaking (Woman p.420; Robertson and Lyons 2003).

\section{Powerless}

A sense of powerlessness was evident across the accounts of women and family members. In the early stages, women were reliant on family, friends and healthcare staff for information and support which often left them feeling 'helpless and disempowered' (Author p.160; Heron et al. 2012). Family members regretted things they 'should have' done and felt as though they had 'let the mother down' (Partner p.6; Holford et al. 2018), particularly in relation to their involvement in the women's hospital admission. Family members described being ignored and expressed frustration at being denied information due to patient confidentiality.

\section{Theme 3: realigning old self and new self}

Recovery was described as a lengthy process which involved women making sense of and integrating their experiences, as well as identifying personal strength and adjusting to a new view of self, in the context of being a parent.

\section{A non-linear process}

The ‘very, very long journey' (Woman p.174; Posmontier and Fisher 2013) to recovery was described as following a 'progressive but non-linear trajectory' (Author p.163; Heron et al. 2012). During this process women reported anxiety, uncertainty about the future and periods of low mood and depression, which occasionally necessitated a hospital readmission. Recovery was conceptualised as an 'active process' (Author p.5; McGrath et al. 2013) in which women became motivated 
to develop their understanding and utilised strategies to reduce the risk of further recurrence.

\section{Making sense and integrating the experience}

The ability for women to openly disclose their experience was regarded as important for recovery. In order to make sense of why they had experienced PP, many attempted to organise events in time and sought information about the disorder. Developing their understanding helped to alleviate self-blame. Communicating with others with similar experiences and sharing their story was important to foster feelings of hope and reduce feelings of isolation and self-blame.

Women wanted counselling or psychotherapy for themselves and also the wider family to help express and come to terms with their experience. However, barriers to accessing support were reported, including lack of provision of talking therapies and different needs within the family sometimes hindered women's ability to talk through and integrate their experiences:

He could not understand at times why I just could not pull myself together which annoyed me even more (Woman p.421; Robertson and Lyons 2003).

\section{A 'return to life'}

Women spoke of turning points in which they started to feel more hopeful about the future and made a decision to 'return to life' (Woman p.10; Engqvist and Nilsson 2014). Positive experiences, such as connecting with other women and bonding with the baby helped to enhance women's self-efficacy. Experiences such as these enabled women to feel like 'themselves again' (Author p.424; Robertson and Lyons 2003) and provided hope for the family that recovery was 'within reach' (Author p.13; Engqvist and Nilsson 2014).

Whilst describing the experience of PP as traumatic, some positive aspects were identified. Women reported feeling more confident or stronger in themselves:

Before I just thought well, I'll coast along until whenever and life's not that bad but now I'm not really scared of anything (Woman p.424; Robertson and Lyons 2003).

Women valued those close to them, reported greater empathy and often felt motivated to help others and 'give something back' (Woman p.424; Robertson and Lyons 2003). Family members similarly reported improved relationships, increased empathy, openness and understanding, both in relation to their family member and more generally towards people experiencing mental health difficulties.

\section{Theme 4: social context}

Social context was conceptualised as an integrative theme that both influenced and was influenced by the women's experience of recovery from PP.

\section{Family relationships—a 'double-edged sword'}

Throughout the process of recovery, family were concurrently viewed as a 'source of immense support and a source of worry' (Woman p.161; Heron et al. 2012). Women valued the support provided by family but simultaneously worried about their families' well-being. In the early stages, women expressed guilt for burdening their family and sometimes expressed strain within their relationships. Women reported prioritising their relationship with their child, but sometimes felt this was to the detriment of their other relationships. Partners reflected on their own stress throughout this experience, but felt unable to seek help:

I was an emotional wreck but felt I had to gather myself together for my wife... I could not have any issues, someone had to be strong (Partner p.241; Doucet et al. 2012).

Psychological support for families was needed to help develop family members' understanding of PP, enhance their coping with the additional stress and enable them to know how to respond and cope with fear around relapse:

If my husband had a support group for new fathers to deal with a psychotic wife, it would have changed everything. He would have been far more compassionate had he known about my illness (Woman p.241; Doucet et al. 2012).

\section{Interaction with healthcare professionals}

Interactions with mental health services were perceived by women and family members as both a facilitator and barrier to recovery. In one study, women reported a sense of pressure to appear to be coping; this was associated with a fear of having their baby removed and acted as a barrier to seeking professional input (Plunkett et al. 2016). Some women and family members reported difficulties accessing support, felt there was a divide between hospital and community services and believed there had been little consideration of their needs as a family. Women and family members occasionally felt judged by health care professionals 'You do the smallest thing and, oh no, you're doing it wrong' (Partner p.405; Boddy et al. 2016).

Some reported more positive experiences and felt 'cared for' (Woman p.384; Engqvist et al. 2011). Positive 
experiences improved women's confidence, promoted their relationship with their baby and provided reassurance to the family, many of whom valued the expertise and support provided by healthcare professionals.

\section{Societal expectations of motherhood-'snap out of it'}

Women and family members both highlighted the public's limited understanding of this 'hidden illness' (Woman p.77; Roberts et al. 2018) which was frequently confused with postnatal depression. The lack of awareness by professionals and peers prevented women from seeking and gaining support and left women feeling as though their symptoms were minimised or dismissed. Some women experienced an expectation from their personal network to 'snap out of it' (Woman p.261; Glover et al. 2014) which exacerbated a sense of internal shame and hindered seeking help:

It's a double whammy. Not only the stigma of being mentally ill, you have got the stigma of being a mentally ill mother, a bad mum (Woman p.78; Roberts et al. 2018).

\section{Discussion}

This is the first review to synthesise the qualitative research on the experience of PP and the factors involved in recovery. The findings provide further evidence as to the extreme and distinct nature of PP (Di Florio et al. 2013) in which there are unique aspects to recovery that should be recognised and inform care provision. The findings of this review reveal that recovery can be a lengthy and non-linear process that continues beyond acute symptom remission and is influenced by the wider social context. Furthermore, the review reveals similarities in the experiences of women and family members, including a reported sense of shock, fear for the future, hopelessness and difficulties in coping and seeking help.

During the early phase, the distressing nature of PP left women and family members struggling to identify what was wrong and unable to access information. Perceived societal stigma and fear of negative repercussions delayed help-seeking behaviour; this may be associated with fear of losing their baby; however, further investigation is required. In their review looking at mental health problems in the postnatal period, Megnin-Viggars et al. (2015) similarly found that women often reached crisis point before seeking help. This finding is important, given the increasing rates of suicide amongst postpartum women experiencing psychosis (Lysell et al. 2018) and the potential negative consequence for the mother-baby relationship (Alhusen et al. 2013). The reported delays in help-seeking behaviour provide further support for NICE (2018) guidelines which highlight the importance of healthcare professional vigilance to possible symptoms of PP and provision of prompt assessment and intervention.

The findings reveal contact with healthcare services is inconsistent and can even hinder accessing support, suggesting that NICE guidelines are not being consistently met. This may reflect differences in service provision, including insufficient availability of specialist MBUs which can result in delays receiving appropriate help (Hill et al. 2019; Jones and Smith 2009). It was also found that the needs as a family were often not adequately addressed, echoing work in the broader area of maternal mental health (Megnin-Viggars et al. 2015; Dolman et al. 2013) and providing further evidence to provide healthcare staff with specialised training on PP to enhance their skills and confidence (Dolman et al. 2013).

Perceived loss has featured in previous reviews relating to severe maternal mental health disorders (Smith et al. 2018; Wittkowski et al. 2014; Dolman et al. 2013). However, for women and families experiencing PP, the sense of loss was pervasive and reported across multiple domains of women's lives. Women feared losing their child and reported loss of time, control, freedom and perceived loss of subsequent children. These losses all disrupted the women's adjustment to motherhood. Time and support were needed to reflect on these losses and to explore their new identity. Dolman et al. (2013) similarly found that women experiencing severe mental health disorders during motherhood need to integrate their 'dual identity' of being a 'woman with a mental illness' and a 'mother' for successful transition to occur. Furthermore, across the studies, women and partners reported a sense of loss in relation to their decision-making about future pregnancies. Although NICE (2018) guidelines recommend providing preconception advice for those at risk of mental health problems, the findings of this review suggest this support may need to be more proactive and ensure the emotional impact of this decision is incorporated.

The centrality of family support was clearly communicated throughout participants' narratives and confirms previous reports that family plays a 'key role' (p.3; Plunkett et al. 2016). Differences were noted in the family members' ability to cope and provide the level of support needed to manage at home. Improved understanding of postnatal mental health problems has been found to influence the relationship and can result in greater resilience and confidence by the partner (Ruffell et al. 2019). The importance of involving the family by providing information and fostering feelings of security and hope has also been reported by professionals working with women experiencing PP (Engqvist and Nilsson 2013b; Engqvist et al. 2007). However, as family perceived a need to be 'strong', this sometimes acted as a barrier to seeking additional external help for themselves. 


\section{Clinical implications}

In order to improve outcomes and facilitate women's recovery, recommendations based on women's and family members' reported experiences are provided in Table 5. Additional recommendations are suggested for healthcare professionals. However, given that the included studies did not report on the views of healthcare providers, these recommendations should be treated with some caution.

\section{Strengths and limitations}

The use of thematic synthesis for this review enhanced the rigour and transparency of the analysis. It allowed for the incorporation of multiple findings and the subsequent offer of a new interpretation which can be used to inform improvements in clinical practice. The systematic search was comprehensive, minimizing language and publication biases. All studies included were of high methodological quality, thereby enhancing the trustworthiness of the data synthesised. Furthermore, steps were taken to maximize transparency and enhance rigour, including the use of data management software and independent reviewers (Tong et al. 2012).

The findings report on the experiences of 103 women and 42 family members and capture a broad range of experiences up to 32 years postpartum. This is viewed as a strength of the review, because it allowed for the analysis and interpretation of a diverse range of views and experiences. However, it was not possible to investigate individuals' experiences specifically in relation to their stage of recovery. It is therefore unclear how an individual's perspective may change over time.
Despite not limiting studies by language, only research from the UK, USA, Canada and Sweden, was identified. This means that the experiences of women and family living in other countries, including less developed countries, perhaps with different family structures and healthcare systems are unknown. Caution is therefore advised when generalizing findings. Despite applying no limits on date, no research pre-dated 2003. This may reflect the poor representation of qualitative research in medical literature (Shuval et al. 2011) which is now on the increase due to an increased recognition on its value (Popay 2006). Furthermore, the analysis is limited to the information provided in the studies included in this review. Other topics which may be pertinent, for example, regarding the types of services accessed, were often not clearly stated.

\section{Further research}

This review highlights a number of gaps in the literature in which further research is needed. Research should focus on the types of long-term psychological and psychosocial interventions that women may find helpful during their recovery from an episode of PP. Exploration may be required to further understand the professional perspective and how this can be integrated into the conceptual model. Family support could be investigated due to their influential role, with emphasis on how to support and enhance their position. It may also be helpful to investigate the experiences of women with different types of family and healthcare support, and to explore the perceived barriers and facilitators to accessing professional input. Finally, it may be useful to explore the impact of preconception counselling and to investigate the factors involved in accessing this type of support.

Table 5 Suggested clinical implications and recommendations

\begin{tabular}{|c|c|}
\hline Women & $\begin{array}{l}\text { - Accurate information should be provided, alongside access to peer support to help normalise women's experiences. } \\
\text { - Women could be offered psychological and psychosocial input during the latter stages of recovery not just the early stages. } \\
\text { - Longer term psychological needs should be considered, incorporating the reported feelings of guilt, loss and difficulties } \\
\text { transitioning to their new perceived role. } \\
\text { - Practical considerations are required to enable access to psychological support, this should be flexible and consider childcare } \\
\text { provision. }\end{array}$ \\
\hline Family & $\begin{array}{l}\text { - The needs of the family should be considered and incorporated into any assessment and intervention plan as much as possible. } \\
\text { - Family members' wellbeing should be monitored and they should be signposted to appropriate support and peer networks as } \\
\text { required. } \\
\text { - Family members should be informed of reputable sources to obtain accurate information. } \\
\text { - Families may benefit from a therapeutic space in which they can openly explore and seek to resolve any difficulties within their } \\
\text { relationships. }\end{array}$ \\
\hline $\begin{array}{l}\text { Healthcare } \\
\text { professionals }\end{array}$ & $\begin{array}{l}\text { - Specialist training and support may help to develop healthcare professionals' confidence and competence meeting the complex } \\
\text { needs of women experiencing PP and their family. } \\
\text { - It is important that professionals maintain a compassionate and non-judgmental stance; in order to develop a therapeutic } \\
\text { relationship which promotes optimism and hope for the future. } \\
\text { - Healthcare professionals should pay particular attention to women who do not have supportive family structures in place. } \\
\text { - Help-seeking behaviour should be targeted; for example, through the provision of accurate information (e.g. during antenatal } \\
\text { classes) and by improving public awareness of PP. }\end{array}$ \\
\hline
\end{tabular}




\section{Conclusions}

The review reveals the complexity of recovery from PP and the need for intervention to be incorporated into a longer term recovery plan, which includes psychological and psychosocial needs alongside medical management. The results highlight the core need for women to assimilate and adjust to their new role as a mother, whilst integrating their experience of PP and associated sense of loss, which could be facilitated through psychological input. The review further depicts a central role for family and reveals an overlap in their reported experiences, suggesting that more input should be provided in collaboration with the family, with the aim to enhance their relationships and ways of coping. The findings also highlight the importance of healthcare professionals providing a timely assessment and providing the necessary support which incorporates the needs of the woman, baby and family.

Authors' contributions All authors contributed to the research design based on an initial idea by AW. RF completed the literature search and data analysis, with input from SP and AW. RF wrote the first draft of the manuscript and SP and AW contributed to and have approved the final manuscript.

\section{Compliance with ethical standards}

Ethics approval As this is a review of secondary data, this article does not contain any studies with human participants performed by any of the authors.

Conflict of interest The authors declare that they have no conflict of interest.

Open Access This article is licensed under a Creative Commons Attribution 4.0 International License, which permits use, sharing, adaptation, distribution and reproduction in any medium or format, as long as you give appropriate credit to the original author(s) and the source, provide a link to the Creative Commons licence, and indicate if changes were made. The images or other third party material in this article are included in the article's Creative Commons licence, unless indicated otherwise in a credit line to the material. If material is not included in the article's Creative Commons licence and your intended use is not permitted by statutory regulation or exceeds the permitted use, you will need to obtain permission directly from the copyright holder. To view a copy of this licence, visit http://creativecommons.org/licenses/by/4.0/.

\section{References}

Alhusen JL, Hayat MJ, Gross D (2013) A longitudinal study of maternal attachment and infant developmental outcomes. Arch Womens Ment Health 16:521-529. https://doi.org/10.1007/s00737-0130357-8

Bergink V, Burgerhout KM, Koorengevel KM, Kamperman AM, Hoogendijk WJ, Lambregtse-van den Berg MP, Kushner SA (2015) Treatment of psychosis and mania in the postpartum period. Am J Psychiatry 172:115-123. https://doi.org/10.1176/appi.ajp. 2014.13121652
Boddy R, Gordon C, MacCallum F, McGuinness M (2016) Men's experiences of having a partner who requires Mother and Baby Unit admission for first episode postpartum psychosis. J Adv Nursing 73(2):399-409. https://doi.org/10.1111/jan.13110

Braun V, Clarke V (2006) Using thematic analysis in Psychology. Qual Res Psychol 3:77-101.https://doi.org/10.1191/ 1478088706qp063oa

Burgerhout KM, Kamperman AM, Roza SJ, Lambregtse-Van den Berg MP, Koorengevel KM, Hoogendijk WJG, Kushner SA, Bergink V (2017) Functional recovery after postpartum psychosis: a prospective longitudinal study. J Clin Psychiatry 78(1):122-128. https://doi. org/10.4088/JCP. $15 \mathrm{~m} 10204$

Charmaz K (2006) Constructing grounded theory: a practical guide through qualitative analysis. Sage Publications, London

Cooke A, Smith D, Booth A (2012) Beyond PICO: the SPIDER tool for qualitative evidence synthesis. Qual Health Res 22(10):1435-1443. https://doi.org/10.1177/1049732312452938

Creswell JW, Miller DL (2000) Determining validity in qualitative inquiry. Theory Pract 39(3):124-130. https://doi.org/10.1207/ s15430421tip3903 2

Critical Appraisal Skills Programme CASP; (2018) Qualitative research checklist. https://casp-uk.net/casp-tools-checklists/. Accessed 18 January 2019

Di Florio A, Smith S, Jones I (2013) Postpartum psychosis. Obstet Gynaecol 15(3):145-150. https://doi.org/10.1111/tog.12041

Dolman C, Jones I, Howard LM (2013) Pre-conception to parenting: a systematic review and meta-synthesis of the qualitative literature on motherhood for women with severe mental illness. Arch Womens Ment Health 16(3):173-196. https://doi.org/10.1007/s00737-0130336-0

Doucet S, Jones I, Letourneau N, Dennis C, Blackmore E (2011) Interventions for the prevention and treatment of postpartum psychosis: a systematic review. Arch Womens Ment Health 14(2):89 98. https://doi.org/10.1007/s00737-010-0199-6

Doucet S, Letourneau N, Blackmore ER (2012) Support needs of mothers who experience postpartum psychosis and their partners. J Obstet Gynaecol Neonatal Nurs 41(2):236-245. https://doi.org/10.1111/j. 1552-6909.2011.01329.x

Engqvist I, Nilsson K (2013a) Experiences of the first days of postpartum psychosis: an interview study with women and next of kin in Sweden. Issues Ment Health Nurs 34(2):82-89. https://doi.org/10. 3109/01612840.2012.723301

Engqvist I, Nilsson K (2013b) Involving the family in the care and treatment of women with postpartum psychosis: Swedish psychiatrists' experiences. Psychiatry J 897084 https://doi.org/10.1155/2013/ 897084

Engqvist I, Nilsson K (2014) The recovery process of postpartum psychosis from both woman's and next of kin's perspective - an interview study in Sweden. Open Nurs J 8:8-16. https://doi.org/10.2174/ 1874434601408010008

Engqvist I, Nilsson A, Nilsson K, Sjöström B (2007) Strategies in caring for women with postpartum psychosis - an interview study with psychiatric nurses. J Clin Nurs 16(7):1333-1342. https://doi.org/ 10.1111/j.1365-2702.2007.01717.x

Engqvist I, Ferszt G, Ahlin A, Nilsson K (2011) Women's experiences of postpartum psychotic experiences - analyses of narratives from the internet. Arch Psychiatr Nurs 25(5):376-387. https://doi.org/10. 1016/j.apnu.2010.12.003

Gee JP (1991) A linguistic approach to narrative. J Narrat Life Hist 1(1): 15-39. https://doi.org/10.1075/jnlh.1.1.03ali

Gillham R, Wittkowski A (2015) Outcomes for women admitted to a mother and baby unit: a systematic review. Int J Women's Health 30(7):459-476. https://doi.org/10.2147/IJWH.S69472

Glaser BG, Strauss AL (1967) The discovery of grounded theory. Aldine, Chicago 
Glover L, Jomeen J, Urquhart T, Martin CR (2014) Puerperal psychosis a qualitative study of women's experiences. J Reprod Infant Psychol 32(3):254-269. https://doi.org/10.1080/02646838.2014.883597

Graneheim UH, Lundman B (2004) Qualitative content analysis in nursing research: concepts, procedures and measures to achieve trustworthiness. Nurse Educ Today 24(2):105-112. https://doi.org/10. 1016/j.nedt.2003.10.001

Hannes K (2011) Chapter 4: critical appraisal of qualitative research. In: Noyes J, Booth A, Hannes K, Harden A, Harris J, Lewin S, Lockwood C (Editors) Supplementary Guidance for Inclusion of Qualitative Research in Cochrane Systematic Reviews of Interventions. Version 1 (updated August 2011). Cochrane Collaboration Qualitative Methods Group 2011. http://cqrmg. cochrane.org/supplemental-handbook-guidance. Accessed on 25th January 2019

Heron J, McGuinness M, Blackmore ER, Craddock N, Jones I (2008) Early postpartum symptoms in puerperal psychosis. BJOG 115(3): 348-353. https://doi.org/10.1111/j.1471-0528.2007.01563.x

Heron J, Gilbert N, Dolman C, Shah C, Beare I, Dearden S, Muckelroy N, Jones I, Ives J (2012) Information and support needs during recovery from postpartum psychosis. Arch Womens Ment Health 15(3): 155-165. https://doi.org/10.1007/s00737-012-0267-1

Hill R, Law D, Yellend C, Williams AS (2019) Treatment of postpartum psychosis in a mother-baby unit: do both mother and baby benefit? Australas Psychiatry 27(2):121-124. https://doi.org/10.1177/ 1039856218822743

Holford N, Channon S, Heron J, Jones I (2018) The impact of postpartum psychosis on partners. BMC Pregnancy Childbirth 18(1):414. https://doi.org/10.1186/s12884-018-2055-z

Horsley T, Dingwall O, Sampson M (2011) Checking reference lists to find additional studies for systematic reviews. Cochrane Database Syst Rev 10(8). https://doi.org/10.1002/14651858.MR000026.pub2

Jones I, Smith S (2009) Puerperal psychosis: identifying and caring for women at risk. Adv Psychiatr Treat 15(6):411-418. https://doi.org/ 10.1192/apt.bp.107.004333

Krippendorff K (2004) Content analysis. An introduction to its methodology. Sage publications, Thousand Oaks

Lachal J, Revah-Levy A, Orri M, Moro MR (2017) Metasynthesis: an original method to synthesize qualitative literature in psychiatry. Front Psychiatry 8:269. https://doi.org/10.3389/fpsyt.2017.00269

Lincoln YS, Guba EG (1985) Naturalistic inquiry. Sage Publications, Newbury Park

Lysell H, Dahlin M, Viktorin A, Ljungberg E, D'Onofrio BM, Dickman P, Runeson B (2018) Maternal suicide - register based study of all suicides occurring after delivery in Sweden 1974-2009. PLoS One 13(1):1-8. https://doi.org/10.1371/journal.pone.0190133

McGrath L, Peters S, Wieck A, Wittkowski A (2013) The process of recovery in women who experienced psychosis following childbirth. BMC Psychiatry 13(341):1-10. https://doi.org/10.1186/ 1471-244X-13-341

McHugh ML (2012) Interrater reliability: the kappa statistic. Biochem Med 22(3):276-282. https://doi.org/10.11613/BM.2012.031

Megnin-Viggars O, Symington I, Howard LM, Pilling S (2015) Experience of care for mental health problems in the antenatal or postnatal period for women in the UK: a systematic review and meta-synthesis of qualitative research. Arch Womens Ment Health 18(6):745-759. https://doi.org/10.1007/s00737-015-0548-6

Mohamied F (2019) Postpartum psychosis and management: a case study. BJM 27(2):77-84. https://doi.org/10.12968/bjom.2019.27.2. 77

Moher D, Liberati A, Tetzlaff J, Altman DG, The PRISMA Group (2009) Preferred reporting items for systematic reviews and meta-analyses: the PRISMA statement. PLoS Med 21:6. https://doi.org/10.1371/ journal.pmed.1000097

Moore GF, Audrey S, Barker M, Bond L, Bonell C, Hardeman W, Moore L, O'cathain A, Tinati T, Wight D, Baird J (2015) Process evaluation of complex interventions: Medical Research Council guidance. BMJ 350:1-7. https://doi.org/10.1136/bmj.h1258

Nager A, Szulkin R, Johansson SE, Johansson LM, Sundquist K (2013) High lifelong relapse rate of psychiatric disorders among women with postpartum psychosis. Nord J Psychiatry 67(1):53-58. https:// doi.org/10.3109/08039488.2012.675590

National Institute for Clinical Excellence (2018) Antenatal and postnatal mental health: clinical management and service guidance. The NICE guideline on clinical management and service guidance. Updated edition. National Collaborating Centre for Mental Health: https:// www.nice.org.uk/guidance/cg192/evidence/full-guideline-pdf4840896925. Accessed on 10 December 2018

Noyes J, Booth A, Flemming K, Garside R, Harden A, Lewin S, Pantoja T, Hannes K, Cargo M, Thomas J (2018) Cochrane Qualitative and Implementation Methods Group guidance series - paper 3: methods for assessing methodological limitations, data extraction and synthesis, and confidence in synthesized qualitative findings. J Clin Epidemiol 97:49-58. https://doi.org/10.1016/j.jclinepi.2017.06.020

NVIVO qualitative data analysis Software; QSR International Pty Ltd. Version 12, 2018

Plunkett C, Peters S, Wittkowski S (2016) Mothers' experiences of recovery from postnatal mental illness: a systematic review of the qualitative literature and metasynthesis. JSM Anxiety Depression 1(4)

Plunkett C, Peters S, Wieck A, Wittkowski A (2017) A qualitative investigation in the role of the baby in recovery from postpartum psychosis. Clin Psychol Psychother 24(5):1099-1108. https://doi.org/10. 1002/cpp.2074

Popay J (2006) Moving beyond effectiveness in evidence synthesis. Methodological issues in the synthesis of diverse sources of evidence. National Institute for Health and Clinical Excellence, London

Posmontier B, Fisher KM (2013) A narratology of postpartum psychosis in an Orthodox Jewish woman. Perspect Psychiatr Care 50(3):167177. https://doi.org/10.1111/ppc.12037

Ring N, Ritchie K, Mandava L, Jepson R (2011) A guide to synthesizing qualitative research for researchers undertaking health technology assessments and systematic reviews. NHS Quality Improvement Scotland file:///C:/Users/bec f/Downloads/ SynthrQualResearchMarch2011.pdf. Accessed on 10 March 2019

Roberts L, Berrisford G, Heron J, Jones L, Jones I, Dolman C, Lane DA (2018) Qualitative exploration of the effect of a television soap opera storyline on women with experience of postpartum psychosis. BJPsych Open 19(4):75-82. https://doi.org/10.1192/bjo.2018.9

Robertson E, Lyons A (2003) Living with puerperal psychosis: a qualitative analysis. Psychol Psychother 76:411-431. https://doi.org/10. 1348/147608303770584755

Robertson E, Jones I, Haque S, Holder R, Craddock N (2005) Risk of puerperal and non-puerperal recurrence of illness following bipolar affective puerperal (post-partum) psychosis. Br J Psychiatry 186: 258-259. https://doi.org/10.1192/bjp.186.3.258

Ruffell B, Smith DM, Wittkowski A (2019) The experiences of male partners of women with postnatal mental health problems: a systematic review and thematic synthesis. J Child Fam Stud 28(10):27722792. https://doi.org/10.1007/s10826-019-01496-4

Shuval K, Harker K, Roudsari B, Groce NE, Mills B, Siddiqi Z, Shachak A (2011) Is qualitative research second class science? A quantitative longitudinal examination of qualitative research in medical journals. PLoS One 6(2). https://doi.org/10.1371/journal.pone.0016937

Silverman D (2006) Interpreting qualitative data: methods for analyzing talk, text, and interaction. Sage Publications Ltd, London

Sit D, Rothchild AJ, Wisner KL (2006) A review of postpartum psychosis. J Women's Health 15(4):352-368. https://doi.org/10.1089/jwh. 2006.15.352

Smith JA, Flowers P, Larkin M (2009) Interpretative phenomenological analysis: theory, method and research. Sage Publications, London

Smith MS, Lawrence V, Sadler E, Easter A (2018) Barriers to accessing mental health services for women with perinatal mental illness: 
systematic review and meta-synthesis of qualitative studies in the UK. BMJ Open 9:1-8. https://doi.org/10.1136/bmjopen-2018024803

Stockley R (2018) Women's experiences of postpartum psychosis during the onset and early days. J Prenat Perinat Psychol Health 33(2):146166

Thomas J, Harden A (2008) Methods for the thematic synthesis of qualitative research in systematic reviews. BMC Med Res Methodol 8: 45. https://doi.org/10.1186/1471-2288-8-45

Tong A, Flemming K, McInnes E, Oliver S, Craig J (2012) Enhancing transparency in reporting the synthesis of qualitative research: ENTREQ. BMC Med Res Methodol 27(12):181. https://doi.org/ 10.1186/1471-2288-12-181

VanderKruik R, Barreix M, Chou D, Allen T, Say L, Cohen LS, Barbour K, Cecatti JG, Cottler S, Fawole O, Firoz T, Gadama L, Ghérissi A, Gyte G, Hindin M, Jayathilaka A, Kalamar A, Kone Y, Lange I, Magee LA, Mathur A, Binns AM, Morgan M, Munjanja S, Gichuhi GN, Petzold M, Sullivan E, Taulo F, Tunçalp Ö, von Dadelszen P, on behalf of the Maternal Morbidity Working Group (2017) The global prevalence of postpartum psychosis: a systematic review. BMC Psychiatry 17(1):272. https://doi.org/10.1186/s12888-017-1427-7

Wilkinson A, Anderson S, Wheeler SB (2017) Screening for and treating postpartum depression and psychosis: a cost-effectiveness analysis. Matern Child Health J 21(4):903-914. https://doi.org/10.1007/ s10995-016-2192-9

Wittkowski A, McGrath LK, Peters S (2014) Exploring psychosis and bipolar disorder in women: a critical review of the qualitative literature. BMC Psychiatry 14:281. https://doi.org/10.1186/s12888-0140281-0

Wyatt C, Murray C, Davies J, Jomeen J (2015) Postpartum psychosis and relationships: their mutual influence from the perspective of women and significant others. J Reprod Infant Psychol 33(4):426-442. https://doi.org/10.1080/02646838.2015.1027181

Publisher's note Springer Nature remains neutral with regard to jurisdictional claims in published maps and institutional affiliations. 